\title{
Study on the Distribution Characteristics and Detection of Red Tide by Remote Sensing
}

\author{
Seung-Yeol Oh ${ }^{1}$, Heung-Min Kim ${ }^{1}$, Do-Hyun Hwang ${ }^{1}$, Su-Ho Bak ${ }^{1}$, \\ Dae-Hyun $\mathrm{Kim}^{2}$ and Hong-Joo Yoon ${ }^{1 *}$ \\ ${ }^{1}$ Major in the division of Earth's Environmental System Science of Spatial \\ Information Engineering, Pukyong National University, (48513) 45, Yongso-ro, \\ Nam-Gu, Busan, South Korea \\ ${ }^{2}$ Oceantech Co., (10440) 262-29, Hangjuoe-Dong, Deokyang-Gu, Goyang-Si, \\ Gyeonggi-Do, South Korea \\ lyoonhj@pknu.ac.kr*
}

\begin{abstract}
Currently the rise of red tide as another marine environment problem is causing huge economic damages on the coastal waters of Korea every year. Rapid and exact detection is necessary for the minimization of damage derived from the red tide. To improve the weakness and complexity of the existing red tide detection method using ocean color sensor, Red Tide Index (RI) was invented by using band data generated by the Communication, Ocean and Meteorological Satellite (COMS)'s Geostationary Ocean Color Imager (GOCI) Sensor and applied. In the summer of 2013, the red tide appeared in a large scale in the South Sea of Korea and flowed into the East Sea being influenced by the ocean current. The species in red tide were found in the sea water with over $23^{\circ} \mathrm{C}$ of sea temperature; expert's conjectures that the sea temperature over $27{ }^{\circ} \mathrm{C}$ acts as a limiting factor to the survival and accumulation of plankton. When applying RI, the experts could remove the turbid water in the South Sea and the result was similar with the concentration distribution of chlorophyll; these facts suggest the possibility of the red tide detection utilizing band ratio. But due to a lack of field measurement data, the verification of accuracy is not complete. It is considered that the more verification and survey to acquire the field data are needed.
\end{abstract}

Keywords: Red Tide, GOCI, Red Tide Index, Sea Surface Temperature

\section{Introduction}

Red tide is a phenomenon that the seawater gets red by a propagation of phytoplankton in a grand scale; it is one of the serious oceanic problems which are emerging for recent years. In Korea, the coastal areas are suffering from eutrophication as the industries have been developing from the 60s. From the mid 90's, various patterns of red tide are shown depending on the distribution of sea temperature, amount of insolation and nutrient salts.

According to National Institute of Fisheries Science (NIFS) of Korea [1-2], the red tide which appears in the coastal areas in Korea is mainly derived from a species named Cochlodinium polykrikoides. The species gives rise to the damages and is dealt with as a national issue. Not only Korea, but the worldwide coastal areas share the red tide problem and suffer from a harm as mass stranding [3-6].

The usual studies on red tide succeeded to apprehend lots of physiological characteristics of major red tide species; they also were useful to the research on red tide species' response to the environment. The red tide that occurs recently, however, is affected by diverse components as changes of marine weather or pollutions of the coasts by human activity. The occurrence of red tide got even harder to detect [7]. 
Owing to these features of red tide, it is more efficient to detect and handle the occurrence of red tide more quickly and accurately to reduce harms to a minimum rather than trying to predict the red tide. The red tide appears in a varied positions and a grand scope, and it even moves along with the current; the air surveillance in a vessel is not perfectly proper to prevent the damages. Thus the answer would be the detection of red tide utilizing a satellite with high degree of spatio-temporal resolution.

Suh et al. (2000) studied on the correlation between the red tide by $C$. polykrikoides and the sea temperature [8]. And Pasterkamt et al. (2002) detected the red tide by supervised classification of SeaWiFS images [9]. Ahn et al. (2006) also detected the red tide using FPCA and MSD method on the SeaWiFS, NOAA and Landsat-7 ETM+ images [10].

A red tide monitoring method by satellites commonly requires a visible light sensor to estimate the concentration of chlorophyll-a on the sea surface [11-13]. Researchers calculated the outlier of chlorophyll concentration to sort red tide. But when the area with high level of chlorophyll concentration is thought to have red tide, it arouses a lack of accuracy. In case of a detection method that uses supervised classification, researchers should collect the prior information about where the red tide occurs and can barely apply the same method to the other regions.

In this study, we researched the factors that influence on the distribution and diffusion of red tide through the ocean circumstances of where the red tide appeared especially in the period the red tide occurred in a large scale in August 2013. In addition, we have invented Red Tide Index which uses the optical properties of red tide depending on the data from GOCI, an ocean color sensor installed in COMS. Such algorithm has a difference from the usual chlorophyll concentration result; it can utilize a spectrum of red tide and be applied to detection in other area.

\section{Data and Methods}

\subsection{Study Area and Data}
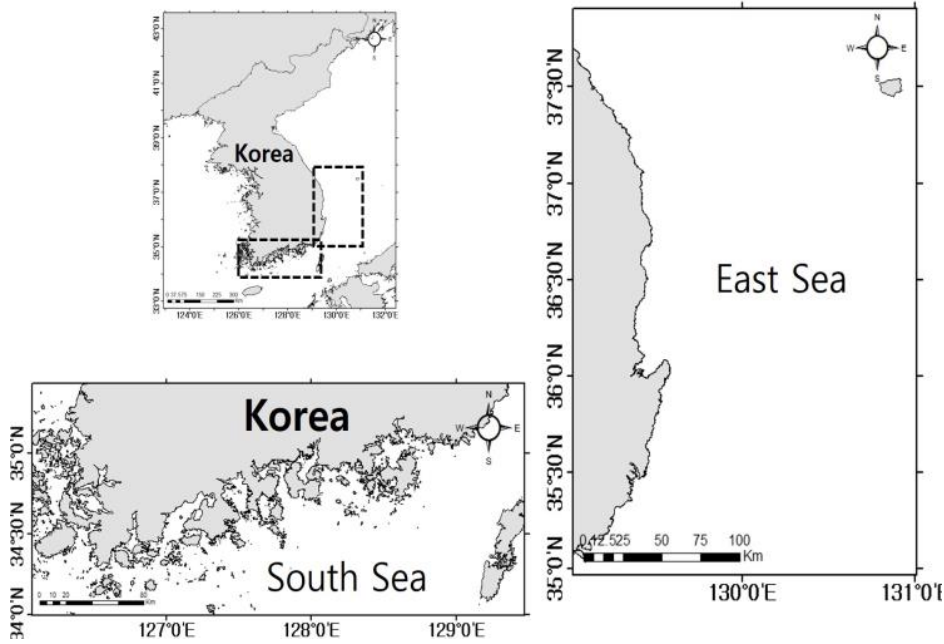

\section{Figure 1. Study Area: The South Sea Gets Economic Damages by the Red Tide Every Year}

The target area of this study was the sea area around the Korean Peninsula where the red tide by $C$. polykrikoides frequently appears and as shown in the Figure 1. For this study, COMS/GOCI data that Korea Ocean Satellite Center (KOSC) offers was used. GOCI shoots the neighboring sea of the Korean Peninsula 8 times a day with 
$500 \mathrm{~m}$ of spatial resolution. It was combined the 8 images of a day into an image, apply the chlorophyll concentration and RI to analysis.

As the information on the occurrence of red tide, we took some news flash about red tide released from NIFS in Korea. A noxious red tide attention and alert is issued when the concentration of $C$. polykrikoides is over 300 cells $/ \mathrm{mL}$ or 1,000 cells/mL respectively.

It was selected some information from the COMS/GOCI data in 12-14 August, when the effect of clouds was small in August 2013 and analysed. GOCI data we used was Level 1B data provided by Korea Institute of Ocean Science \& Technology (KIOST) [14-15]. In 12-14, the red tide appeared in most of areas of the South and East Sea due to $C$. polykrikoides. The highest level of density of red tide species was 20,000 cells $/ \mathrm{mL}$.

\subsection{Red Tide Index}

$\mathrm{RI}$ is a type of numerical value without unit obtained from the combination of band values from a sensor. RI performs as an indicator to assort the clear water and red tide. There are 6 types of water-leaving radiance that we can get from the GOCI sensor: $412 \mathrm{~nm}, 443 \mathrm{~nm}, 490 \mathrm{~nm}, 555 \mathrm{~nm}, 660 \mathrm{~nm}$ and $680 \mathrm{~nm}$ of wavelength band. In this research, we used three bands with $490 \mathrm{~nm}, 555 \mathrm{~nm}$ and $660 \mathrm{~nm}$ of wavelength.
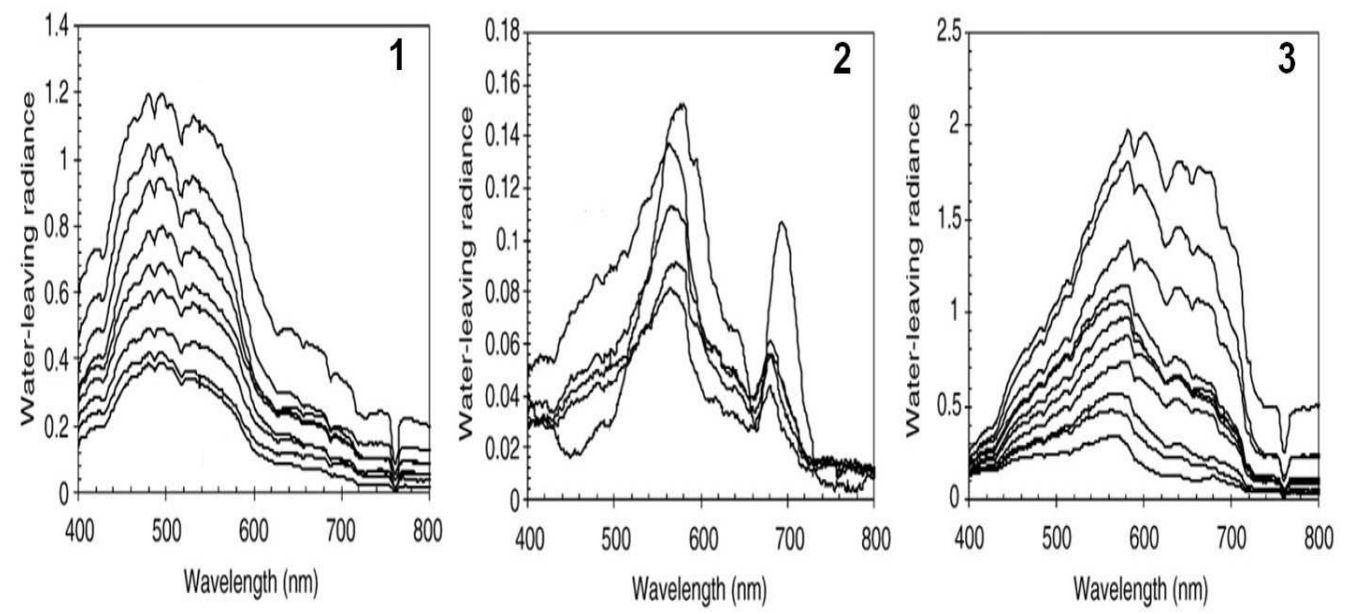

\section{Figure 2. Water-leaving Radiance Data of Clear Water (1), Red Tide (2) and Turbid Water (3) [10]}

Also we divided the degree of sea surface into three: clear water, red tide, and turbid water. The Figure 2 shows a graph that indicates the water-leaving radiance data according to the each condition of sea surface [10]. As shown in the graph, the clear water and the red tide show a great difference in the patterns from $490 \mathrm{~nm}-$ $555 \mathrm{~nm}$ section [16]. These spectroscopic features can draw RI from the formula 1. We called the RI invented for this study NRI to distinguish from the RI used in KIOST which was selected to use in the investigation.

$$
N R I=\frac{555 n m-490 n m}{555 n m+490 n m}
$$

As we can see in the graph, however, the red tide and the turbid water has similar patterns in the $490 \mathrm{~nm}-555 \mathrm{~nm}$ section. Therefore we cannot distinguish the red tide and the turbid water if calculated by the formula 1. To solve this problem, the removal of the turbid water was necessary. The red tide and the turbid water has a 
difference in reflectance in $660 \mathrm{~nm}$ section; an additional formula using $660 \mathrm{~nm}$ is required. The additional formula is in the formula 2.

$N R I=\frac{555 \mathrm{~nm}-490 \mathrm{~nm}}{565 \mathrm{~nm}+490 \mathrm{~nm}}+\frac{555 \mathrm{~nm}-660 \mathrm{~nm}}{565 \mathrm{~nm}+660 \mathrm{~nm}}$

The value minus the value of the turbid water can be obtained through the process. The result theoretically takes a form of index without unit and ranges from -2 to +2 . For the values from NRI, the probability of the red tide rises when the value is larger than 0 . If the value is negative or near 0 , it can be considered not to be the red tide. A proper threshold value needs to be found and applied to distinguish the red tide; the optimal threshold value is determined by experiments.

\section{Result}

\subsection{Red Tide Occurrences}

There was a remarkable red tide in the South Sea of Korea in 2013. It first occurred in 14th July and lasted 50 days to 1 st September. The amount of damage caused by the harmful red tide was estimated over $\$ 20$ million. The red tide even moved to the East Sea region where the red tide hardly occurs through the current. The whole range of red tide was expanded.

The Figure 3 shows the dispersion of chlorophyll concentration in the South Sea of Korea in the analyze period. As mentioned earlier, the chlorophyll concentration itself is not completely capable of detecting the red tide. But the chlorophyll dispersion can be a help to a brief estimate of the red tide. The comparison between the dispersion of chlorophyll concentration and the image analysis of Sea Surface Temperature (SST) from the Figure 4 informs that the temperature of the sea area where the chlorophyll is accumulated is ranging from $23{ }^{\circ} \mathrm{C}$ to $26^{\circ} \mathrm{C}$. It seems like the tide and wind affected to chlorophyll and let it concentrate on the coasts. But the water temperature over $27{ }^{\circ} \mathrm{C}$ is thought to be inappropriate to the survival of chlorophyll. 

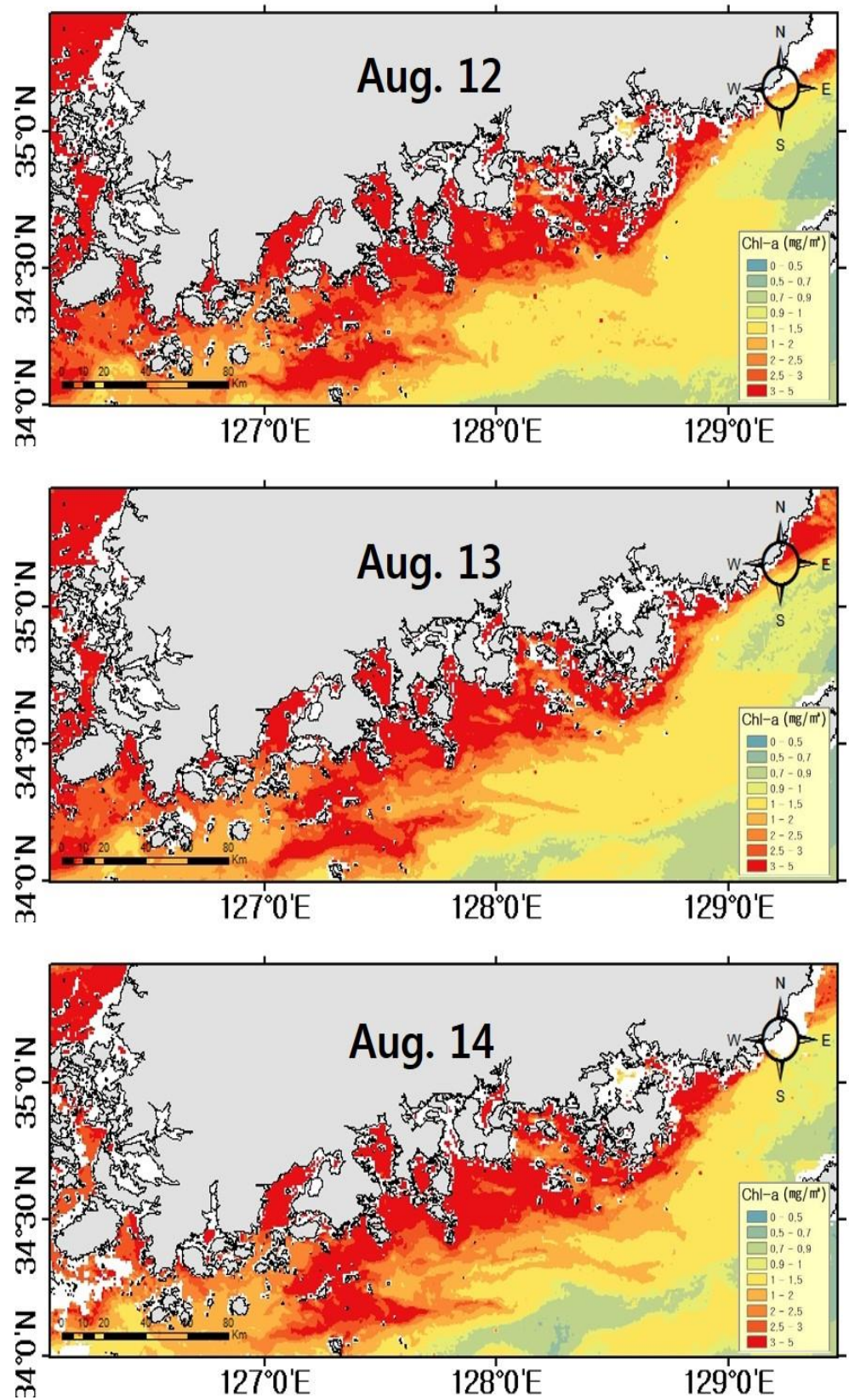

Figure 3. The Distribution of Chlorophyll at the South Sea of the Korean Peninsula in 12-14 August 2013. There Is Often Overestimation of NRI near the Coastal Waters Because of the Turbidity Is Relatively High at the Western Part of the South Sea 

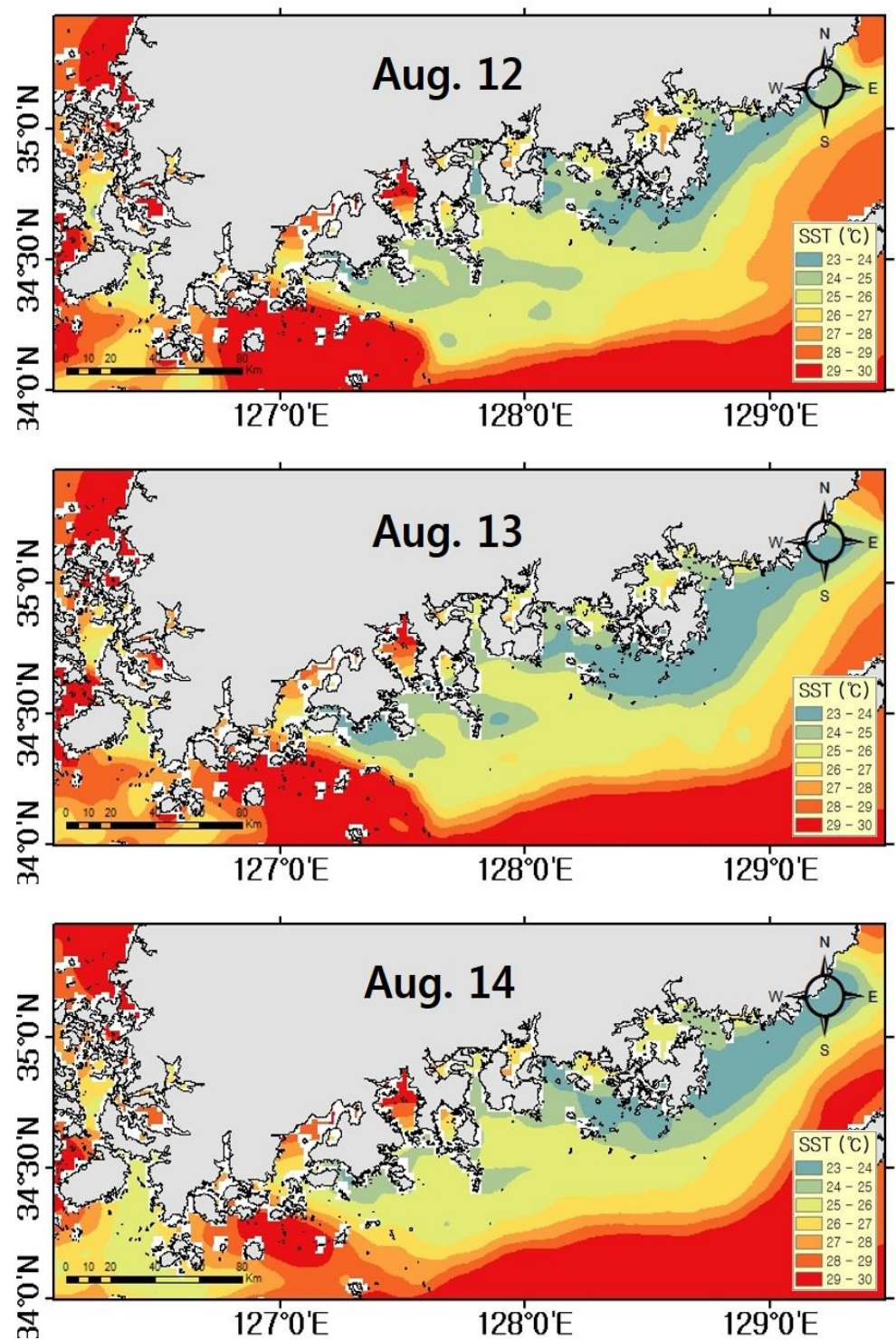

\section{Figure 4. The Distribution of SST at the South Sea in 12-14 August 2013}

The red tide appeared in the Korean Peninsula flowed into the East Sea through the sea currents. In the Figure 5, we can see the dispersion of chlorophyll concentration observed in the East Sea during the experiment period. Chlorophyll which began going north among the coasts failed to going farther at 37 degrees northern latitude and diffused to the east. In case of SST of the East Sea (Figure 6) in the same period, the sea region of higher chlorophyll concentration was the same with that of $23-28^{\circ} \mathrm{C}$ of SST. And there is one example of similar moving pattern; a current moving northward from the South Sea and a current moving southward from the south gather at a certain point but do not combine into one. They just move to the East Sea. In conclusion, the most effective factor to the diffusion of red tide at the East Sea is considered to be sea currents. 

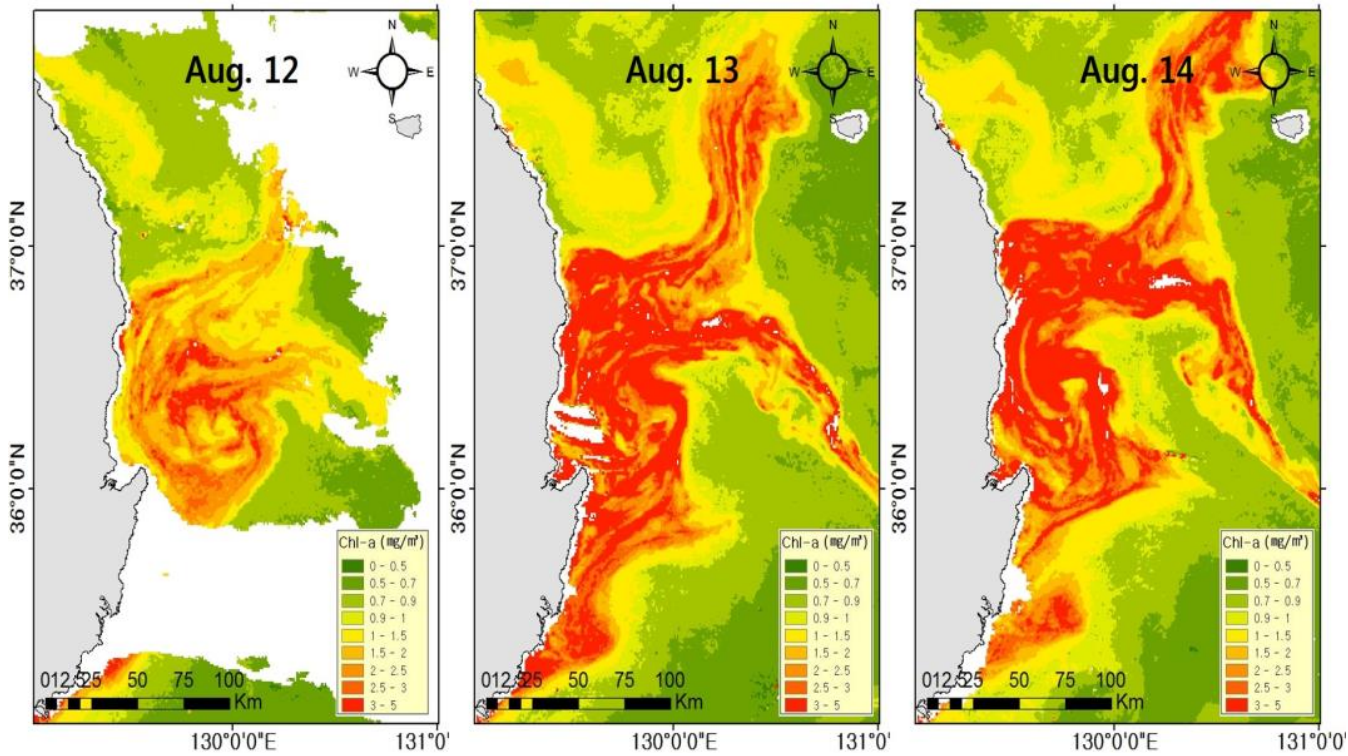

Figure 5. The Distribution of Chlorophyll at the East Sea In 12-14 August 2013
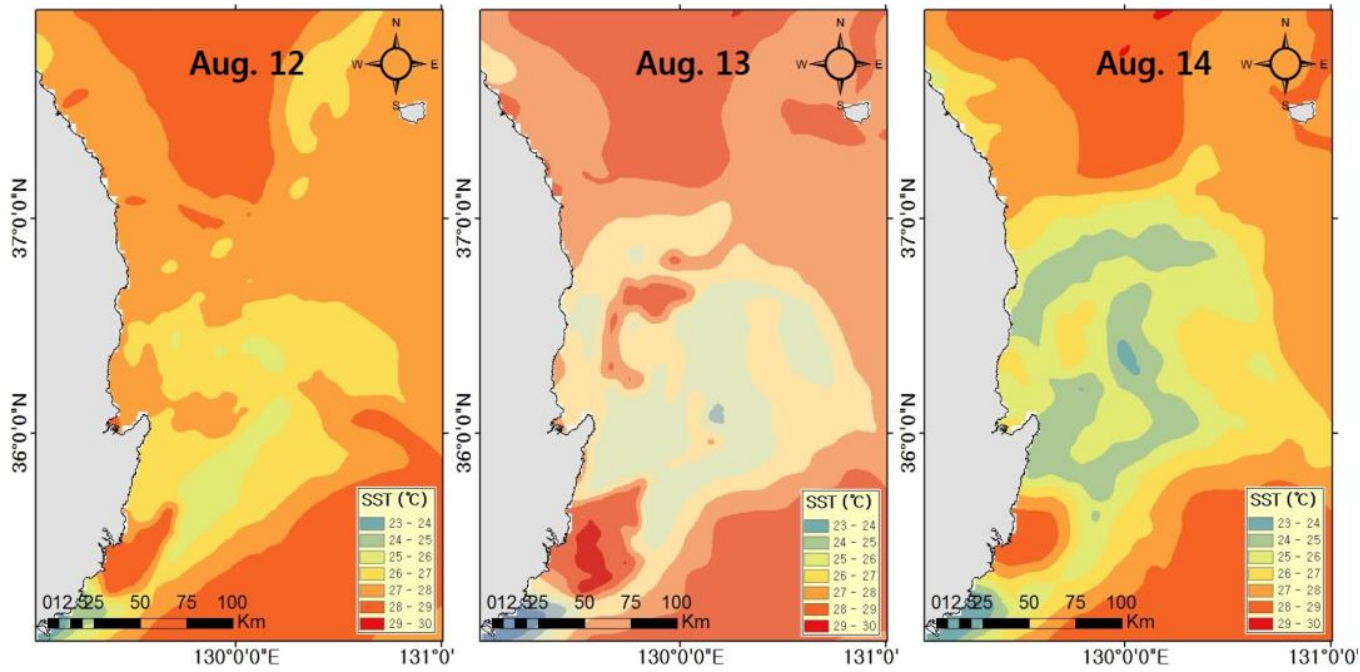

Figure 6. The Distribution of SST at the East Sea in 12-14 August 2013

\subsection{Red Tide Detect Using RI}

Until now, several methods which try to detect the red tide on the basis of chlorophyll concentration estimate were implemented. But the detection techniques need to be reformed depending on the conditions of neighboring waters. Since the usual algorithms of chlorophyll estimate and red tide detection were developed aiming at the clear waters, it was hard to apply the algorithm to the ocean with high degree of turbidity. Thus this study has developed RI, a simple algorithm using a band ratio of GOCI and compare it with RI invented by KIOST. The qualifications of each RI was operated at the East Sea of Korea where the turbid water has very little effect. 
Two indexes were applied to the East Sea; for RI, we could get the result of which the dispersion of chlorophyll concentration is similar with the area where the result is more than 0.2. In the case of NRI, the result was similar with that of the area with more than 0.9 . But there was often overestimation of NRI near the coastal waters. It seems it is because the water-leaving radiance value near the coasts includes complicated optical characteristics.

There is no verification of accuracy performed due to a lack of field data about the red tide on the ocean areas far from the coasts. However we set up the threshold value based on the value similar with that of the red tide areas that can be inferred by the chlorophyll concentration. Each threshold value was 0.2 for RI and 0.9 for NRI.
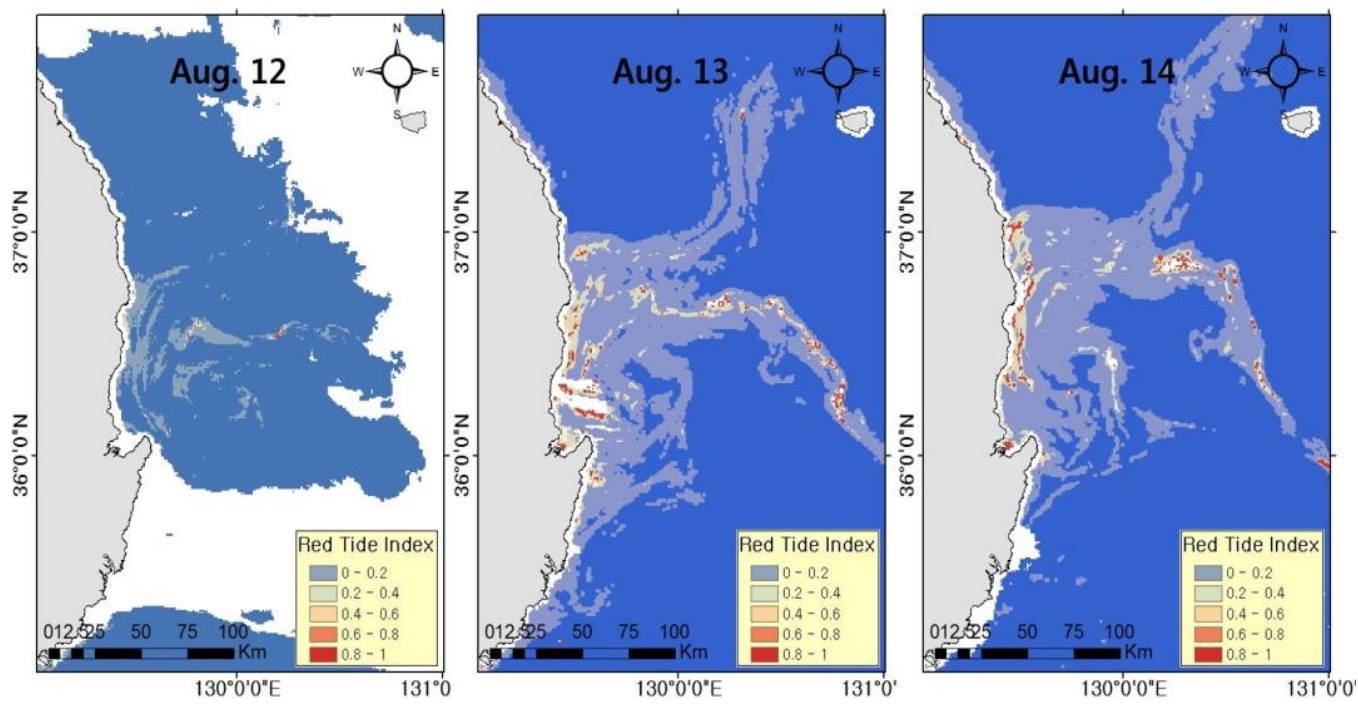

Figure 7. The result of RI at the East Sea in 12-14 August 2013
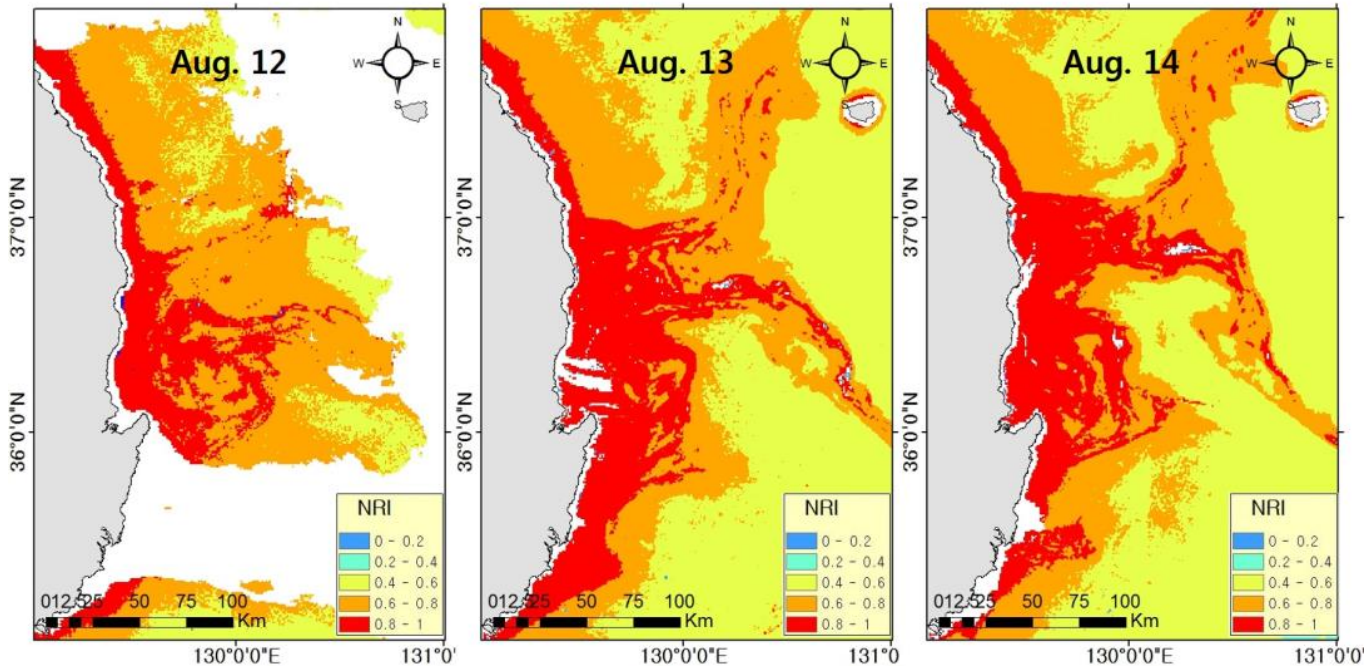

Figure 8. The result of NRI at the East Sea in 12-14 August 2013 
The same algorithm was applied to the South Sea after setting up the threshold value applying to the East Sea. The South Sea gets economic damages by the red tide every year and is typical Case-II water which means the water is low and turbid.

The figure 9 and 10 are the result of analysis on the experimental period applying the settled threshold value to RI and NRI. It is exposed that an overestimated part by the turbid water was removed in the analysis of chlorophyll concentration. The areas thought to be the red tide have a difference in part; for RI, the turbid water part in the western part of the South Sea is completely removed while most of the turbid water area of NRI is removed. It can be also find that the distribution of areas thought to be the red tide is similar with the distribution of chlorophyll.
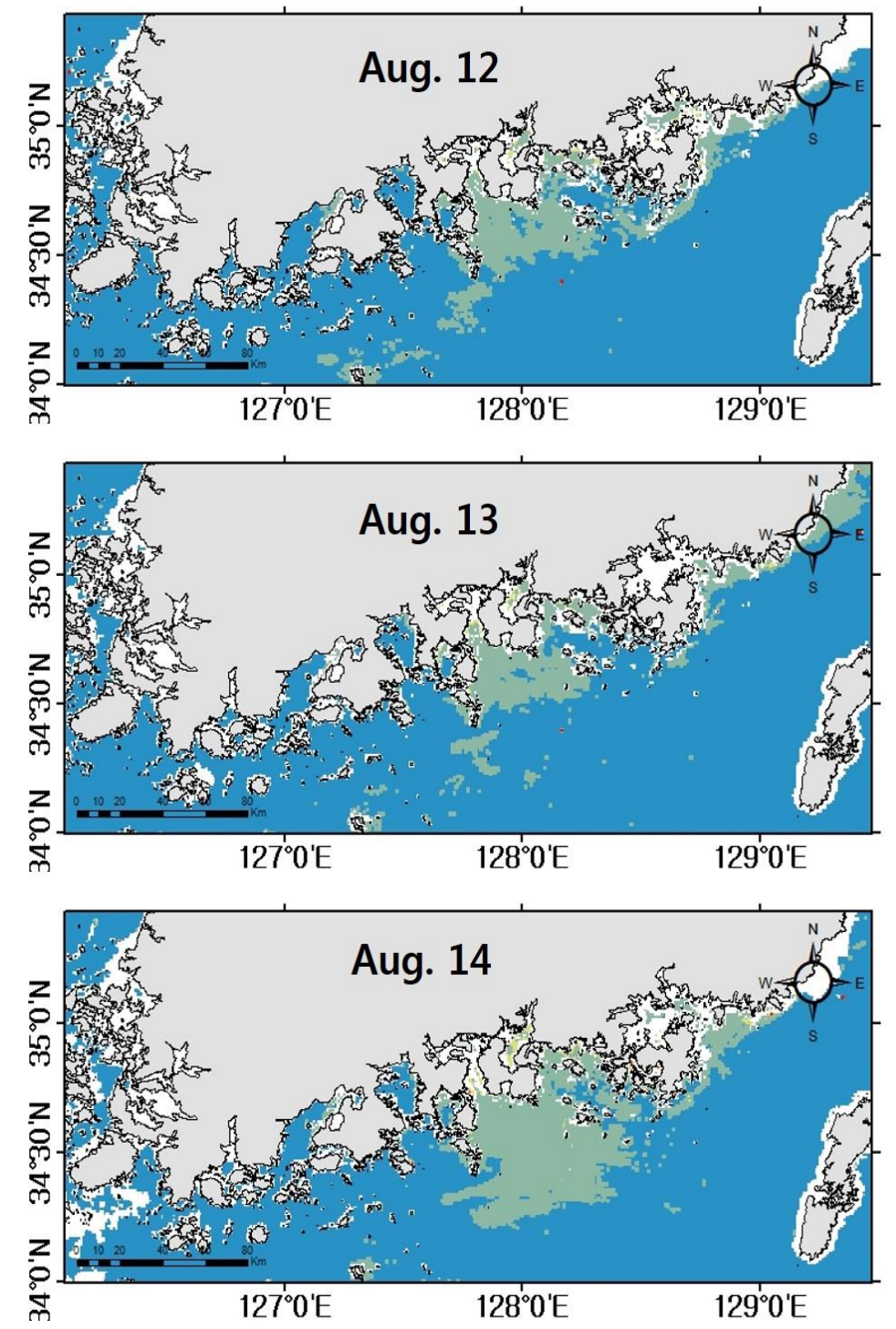

Figure 9. The Result of RI at the South Sea in 12-14 August 2013 

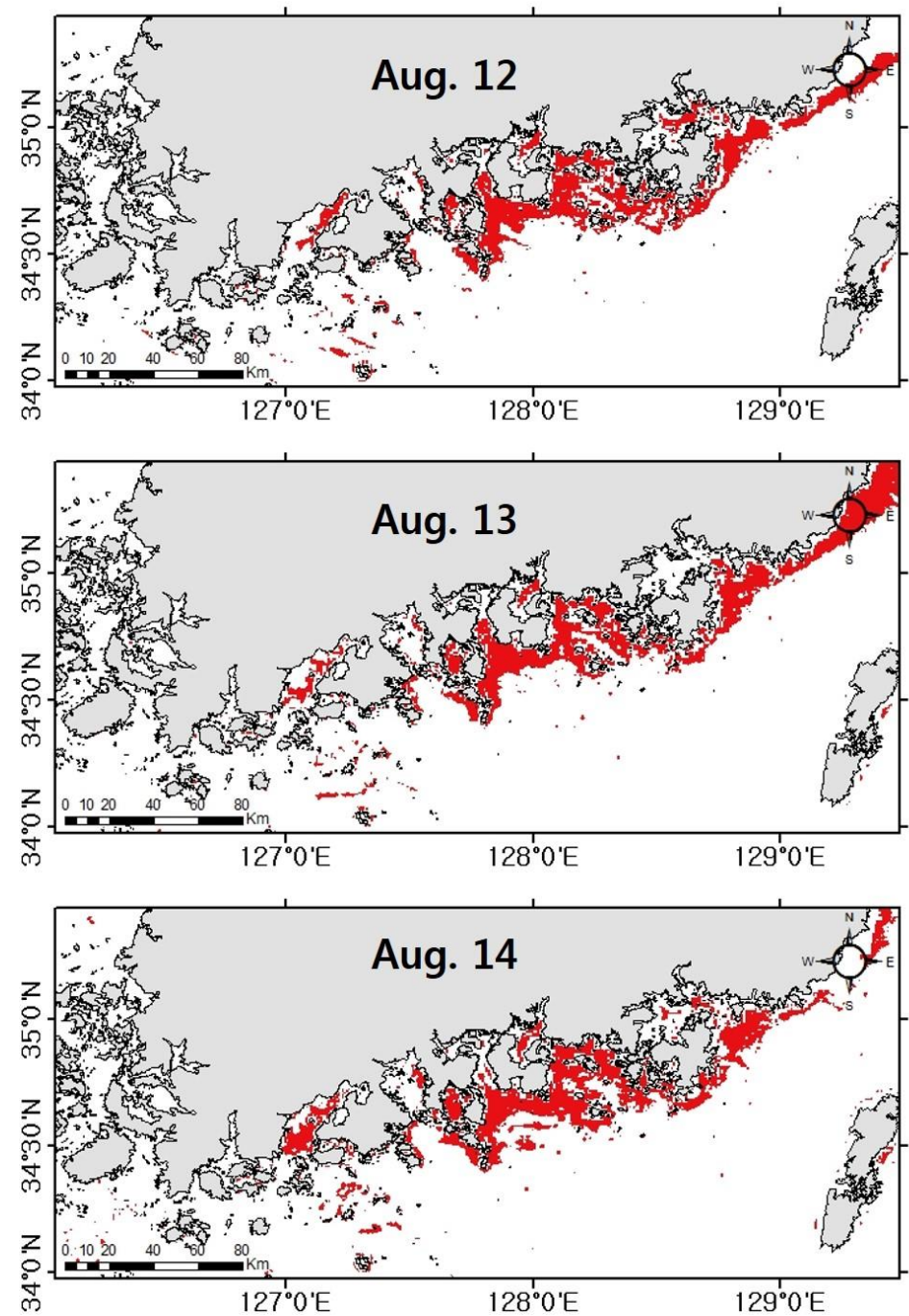

Figure 10. The Result of NRI at the South Sea in 12-14 August 2013

\section{Summary and Conclusion}

This study analyzes the ocean environment and the red tide which occurred and was diffused in a grand scale in the waters of Korea in August 2013. A red tide detection method utilizing a satellite sensor was used.

The red tide appeared at the South Sea and flowed in the East Sea among the sea currents. SAs contrasted with SST, a sea current coming eastward from the South and a current coming southward from the North failed to be combined at where they meet and moved to the East. This leads us to the fact that the most effective factor to the diffusion of red tide at the East Sea is sea currents.

When using the detection method with an ocean color satellite, different from the existing method of chlorophyll concentration, we could calculate RI with a simple band ratio and compare it to RI of KIOST. When setting up a threshold value appropriate to each algorithm and applying it, the turbid water area estimated by RI on the western part of the South Sea was completely removed. On the other hand, the turbid water of NRI was almost completely deleted and the diffusion of red tide area was similar with that of chlorophyll. 
However, field survey data about the ocean area far from the coasts is not enough to thoroughly verify the diffusion of the red tide detected by RI. Additional research which can be applied to various types of ocean with red tide is required. To verify and improve the algorithm, to achieve the actual survey data from wider oceans is necessary as well.

\section{Acknowledgments}

This paper is a revised and expanded version of a paper entitled "Distribution Characteristics and Detection of Red Tide by Remote Sensing" presented at 2016 The $5^{\text {th }}$ International Conference on Next Generation Computer and Information Technology at Harbin on August 19-20.

\section{References}

[1] National Institute of Fisheries Science, "National Report on HABs in Korea", NIFS, (2003).

[2] National Institute of Fisheries Science. "Data on Red Tides", NIFS, (2008).

[3] D. M. Anderson, "Turning back the harmful red tide", Nature 388, (1997), pp. 513-514.

[4] Y. Kang, H. Kim, W. Lim, C. Lee, S. Lee and S. Kim, "An unusual coastal environment and Cochlodinium polykrikoides blooms in 1995 in the South Sea of Korea", J. of the Korean Soc. Of Oceano, vol. 37, no. 4, (2002), pp. 212-223.

[5] D. Jin, E. Thunberg and P. Hoagland, "Economic impact of the 2005 red tide event on commercial shellfish fisheries in New England", Ocean \& Coastal Management, vol. 51, (2008), pp. 420-429.

[6] C. Miao, Y. Tang, H. Zhang, Z. Wu and Wang, "Harmful algae blooms removal from fresh water with modified vermiculite", Environmental Technology, vol. 35, (2014), pp. 340-346.

[7] H. G. Kim, "Harmful Algal Blooms in the Sea", Dasom, (2005).

[8] Y. S. Suh, J. H. Kim and H. G. Kim, "Relationship between Sea Surface Temperature derived from NOAA Satellites and Cochlodinium polykrikoides Red Tide occurrence in Korean Coastal Waters", J. of the Korean Environmental Sciences Society, vol. 9, no. 3, (2000), pp. 215-221.

[9] R. Pasterkamp, S. W. M. Peters, H. J. van der Woerd and H. J. Hoogenboom, "Detection of algae blooms in the north sea using supervised classification of SeaWiFS reflectance imagery", The Seventh International Conference on Remote Sensing for Marine and Coastal Environments, Miami, Florida, (2002), pp. 20-22.

[10] Y. Ahn, P. Shanmugam, J. Ryu and J. Jeong, "Satellite detection of harmful algal bloom occurrences in Korean waters", Harmful Algae News, vol. 5, (2006), pp. 213-231.

[11] C. Hu, F. K. Muller, C. Taylor, K. CarderL, C. Kelble, E. Johns and C. Heil, "Red tide detection and tracing using MODIS fluorescence data: A regional example in SW Florida coastal waters", Remote Sensing of Environment, vol. 97, (2005), pp. 311-321.

[12] J. Ishizaka, Y. Kitaura, Y. Touke, H. Sasaki, A. Tanaka, H. Murakami, T. Suzuki, K. Matsuoka and H. Nakata, "Satellite detection of red ride in Ariake Sound, 1998-2001", J. of Oceanography, vol. 62, (2006), pp. 37-45.

[13] S. Oh, S. Jang, W. Park, J. Lee and H. Yoon, "A comparative study for red tide detection methods using GOCI and MODIS", Korean j. of remote sensing, vol. 29, no. 3, (2013), pp. 331-335.

[14] S. I. Cho, Y. H. Ahn, J. H. Ryu, G. S. Kang and H. S. Youn, "Development of Geostationary Ocean Color Imager (GOCI)", Korean Journal of Remote Sensing, vol. 26, no. 2, (2010), pp. 157-165.

[15] J. H. Ryu, H. J. Han, S. Cho, Y. J. Park and Y. H. Ahn, "Overview of Geostationary Ocean Color Imager (GOCI) and GOCI data Processing System (GDPS)", Ocean Science Journal, vol. 47, no. 3, (2012), pp. 223-233.

[16] Y. B. Son, J. Ishizaka, J. C. Jeong, H. C. Kim and T. Lee, "Cochlodinium polykrikoides red tide detection in the South Sea of Korea using spectral classification of MODIS data", Ocean Science Journal, vol. 46, no. 4, (2011), pp. 239-263.

\section{Authors}

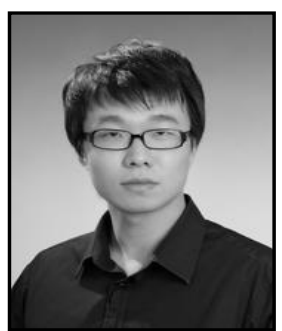

Seung-Yeol Oh, he received the M.S. degree from Dept. of Spatial Information Engineering of Pukyong National University, Busan in 2012. He's doing a Ph.D. course in Dept. of Spatial Information Engineering of Pukyong National University. 

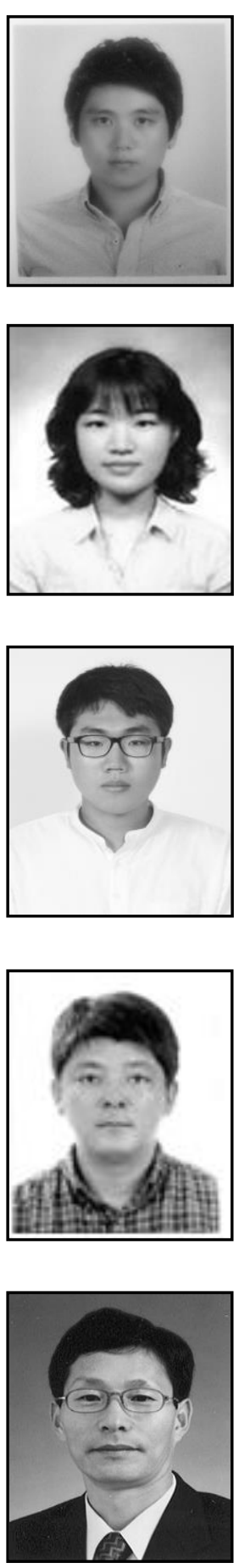

Hong Joo Yoon, he is professor and his academic degrees are Master in Ocean Dynamics (Pukyong National University, Korea), DEA in Atmospheric Dynamics (Paris VI University, France) and Doctor in Geodynamics (Grenoble I University, France). His special fields are Satellite Remote Sensing (Satellite Oceanography and Meteorology) and Marine \& Fisheries GIS. His recently studying the main subjects are change of climate, variations of SSH\&SST, ocean circulation and application of Big data in ocean. 